\title{
The effect of braid angle on the dynamic response of 3-D four direction carbon/epoxy braid composites at high strain rates
}

\author{
Z. H. Tan, B. Jia, B. J. Pang \& B. Z. Gai \\ Hypervelocity Impact Research Center, Harbin Institute of Technology, \\ People's Republic of China
}

\begin{abstract}
In this paper, the compressive properties of two different braid angles of $15^{\circ}$ and $30^{\circ}$ of 3-D four-direction braid carbon/epoxy composites have been investigated to evaluate the compressive failure mode at different strain rates by using the split Hopkinson pressure bar (SHPB). Samples with different braid angles were subjected to a high strain rate compression loading at strain rates, ranging from almost 500/s to 2000/s. A copper disk was selected to use as a pulse shaper to ensure that the stress and strain in the specimen were uniform and deformed at a nearly constant strain rate over most of the dynamic compression duration. The effects of the strain rates and braid angles on peak stress and stiffness were discussed in the study. The results indicated that composites with a braid angle $15^{0}$ had larger peak stress and stiffness at high strain rates.

Keywords: $S H P B$, braid composite material, high strain rate, braid angle, dynamic peak stress.
\end{abstract}

\section{Introduction}

A large number of the applications of composite materials involve dynamic loading during their service life. Deformation and fracture of the composites have received considerable attention. Further, development of a constitutive equation for materials used in structures subjected to dynamic loading requires the knowledge base of the variation in material strength with the applied rate of loading and also how stress and strain rate are related [1, 2]. Hence, it is necessary to characterize the composites' dynamic response at high strain rates. 
Much of the previous research in the fields of high strain rate loading has been performed on unstitched composites and ductile metallic materials. It is only in recent years that significant efforts have been made to examine the high strain rate properties of more brittle materials such as composites, ceramics and so on.

Hosur et al. [3] studied the dynamic response of 32 plies of a DA4518 unidirectional and cross ply carbon/epoxy laminate composites at strain rates of $81,162,817 / \mathrm{s}$. The samples of cross-ply laminate were tested in thickness and in-plane direction. The unidirectional laminate samples were subjected to loading along the 0 and 90 directions. The results indicate that the dynamic strength and stiffness exhibited a considerable increase compared to the quasistatic values. The effects of the fiber direction, strain rate on the strength and failure mode were also analyzed.

El-Habak [4] studied the mechanical behaviour of woven glass fiber reinforced composites at failure strain rates ranging from 100 to $1000 / \mathrm{s}$. The effect of the fiber size, different resin matrix epoxy and vinyl ester on the strength of material was investigated. The results showed that the fibre size does not affect the strength, however, composites made of vinyl ester have greater strength.

Oguni and Ravichandran [5] studied the mechanical behavior of unidirectional fiber reinforced polymer composites (E-glass/vinyl ester) with $30 \%$ and $50 \%$ fiber volume fraction under uniaxial dynamic compression for high strain rates up to 3000/s. The results indicated that the strength increases with increasing strain rates. The results show that the strength of $50 \%$ is greater than that of $30 \%$. Based on the strain rate and volume fraction, a constitutive model was set up.

Wass et al. [6] conducted the static and dynamic response of unidirectional glass/epoxy laminates with varying fiber volume fractions. The results show that the strength of the composites is dependent on the strain rate. The dynamic strength is nearly 1.7 times than that of static. Hsiao and Daniel investigated the strain rate effects on the transverse compression and shear behavior of unidirectional carbon/epoxy laminates. The results show similar trends.

Hosur et al. [7] conducted compressive tests of 37 layers of satin weave carbon/epoxy laminates under off-axis high strain rate loading in in-plane direction along $0^{\circ}, 15^{\circ}, 30^{\circ}, 45^{\circ}, 60^{\circ}, 75^{\circ}$ and $90^{\circ}$. There was a considerable increase in the strength stiffness at high strain rate loading compared to static loading. Ultimate strength and strain of the weave carbon/epoxy composites varied considerably with the orientation of fibers to the loading direction.

Many works have been done on the dynamic response of unidirectional or cross ply laminate at high strain rates. The 3-D braid composite is the so-called third generation composite material compared to the 2-D laminates. 2-D laminates are often deformed and delaminated when subjected to impact loading. In order to improve the resistance of the impact, a 3-D braid composite material is fabricated $[9,10]$. This has been used in aerospace and other specialist fields that involve impact loading. However, the compressive properties of 3-D fourdirection braid composites have so far not been reported. For the different braid 
angle, the carbon volume fraction is different. The effect of the braid angle of composites on the strength is investigated in the paper. Two different braid composites with angles of $15^{\circ}$ and $30^{\circ}$, corresponding fibers volume fraction is $10 \%$ and $30 \%$, were investigated in this study. The dynamic properties of composites were conducted by using a split Hopkinson pressure bar with a pulse shaper along the thickness and transverse directions at high strain rates, up to $2000 / \mathrm{s}$. The effects of the braid angle and the strain rate on the peak stress and stiffness were discussed in this paper.

\section{Experimental procedures}

\subsection{Material and specimen}

The composites with braid angles of $15^{\circ}$ and $30^{\circ}$ with the volume fraction of $10 \%$ and $30 \%$ were selected to study the strain rate effect in this paper. The $12 \mathrm{~K}$ fiber cluster of T300 Carbon fibers were employed to weave the 3-D four-direction fabric. The TDE-85 epoxy resins were injected into the 3-D woven fabric performs by RTM technique and then consolidated into 3-D composites. The thickness of the composites was $9 \mathrm{~mm}$. The small block 3 -D braid composite specimen with two geometry size $9 \times 9 \times 20 \mathrm{~mm}^{3}$ and $9 \times 9 \times 9 \mathrm{~mm}^{3}$ were cut from a carbon/epoxy 3-D four direction braid composite materials for the compression test along the transverse and thickness directions respectively.

\subsection{Split Hopkinson pressure bar}

The split Hopkinson pressure bar (SHPB) has become a very popular experimental technique for the study of dynamic response of materials at high strain rates. A schematic of the set-up is shown in Fig 2. The setup comprises a gas gun chamber, striker bar, incident bar, transmission bar and the strain gauges attached to the incident bar and transmitter bar. When the striker bar impacts the incident bar, an elastic stress compression wave is generated that propagates the incident bar toward the specimen. When the pulse reaches the interface of the incident bar and specimen, part of the stress wave is reflected back into the incident bar and the rest is transmitted through the specimen into the transmission bar. The loading pulse signals are recorded by the gages attached at the middle of the incident bar and the transmission bar.

Based on the well-known one-dimensional analysis of wave propagation in the bars, the axial stress in the specimen, the strain rate and the strain are estimated as follows:

$$
\begin{gathered}
\sigma(t)=\frac{E A_{0}}{A} \varepsilon_{t}(t) \\
\varepsilon(t)=\frac{2 C_{0}}{L_{0}} \int_{0}^{t} \varepsilon_{r}(t) d t \\
\varepsilon(t)=\frac{2 C_{0}}{L_{0}} \varepsilon_{r}(t)
\end{gathered}
$$


where $C_{0}$ is the longitudinal wave velocity in the split Hopkinson bar, $L_{0}$ is the effective gauge length of the specimen and $E$ is the Young's modulus of the bar, while $A$ and $A_{0}$ are the cross-sectional areas of the split bar and specimen respectively.

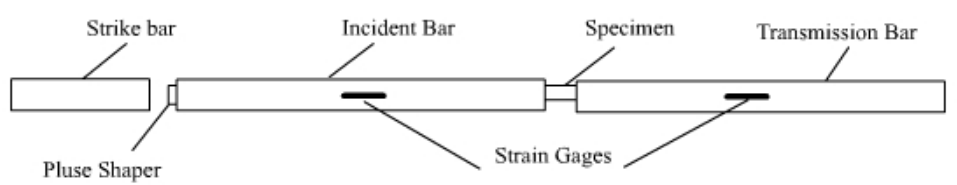

Figure 1: $\quad$ Schematic of split Hopkinson pressure bar.

All of the equations are based on the following hypothesis:

i. Wave propagating in bars can be described by the one-dimensional wave propagating theory;

ii. The specimen inertial effect and friction effect in the test are negligible;

iii. The stress and strain fields in the specimens are uniform and one-dimensional in their axial direction.

We chose a large ratio of diameter to length for the bar and lubrication of the specimen to satisfy the first two assumptions. A copper disk was selected to ensure the stress and strain in the specimen were uniform.

\subsection{Dynamic compression test}

In the present study, a split Hopkinson bar setup was employed for the high strain rate test. The conventional SHPB setup consists of an A2 hardened steel bar with $12.7 \mathrm{~mm}$ in diameter; the striker bar is $150 \mathrm{~mm}$; the incident bar is $1800 \mathrm{~mm}$ long and the transmission bar is $1200 \mathrm{~mm}$. The strain gauges are attached to the middle of the incident bar. The two strain gauges are connected to a Wheatstone bridge circuit in a $1 / 2$ bridge way to nullify axial waves and magnify the bending wave two times. The signals from the bridges are amplified 500 times by AM 502 differential amplifiers, recorded by a Tekronix TDS500 oscilloscope. The data sampling rate is $25 \mathrm{MHz}$ for all SHPB tests in present work.

In order to obtain reliable results, during the test, copper disks were used at the end of the incident bar to precisely control the profile of the loading pulse in order for the specimen to be deformed at a nearly constant strain rate under dynamically equilibrated stress.

\section{Results and discussion}

Experiments were conducted under pressures of $0.6,0.75,0.9$ and $1.05 \mathrm{MPa}$. High strain rate tests were performed on two different braid angles of $15^{\circ}$ and $30^{\circ}$ 
carbon/epoxy composite materials in transverse and thickness directions, respectively. The typical stress wave collected by gauges in these experiments is shown in Fig. 2. The incident wave was changed to a triple wave. There is a flat plateau in the reflected wave, according to eqn (3), the flat meaning that the specimen was a deformed uniform. The reflected wave then goes up, which means the specimen failed and the stress wave reflected completely. At the same time, the transmitted wave decreases to zero.

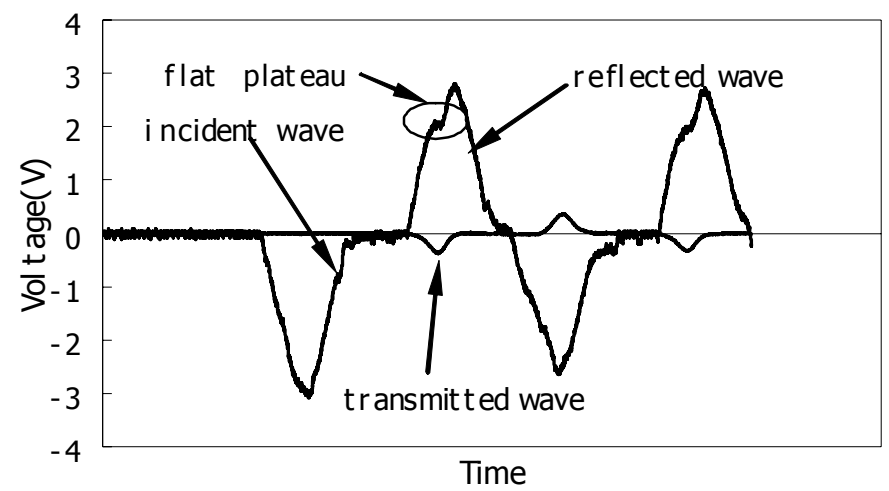

Figure 2: The typical stress wave collected by gauges during the experiment.

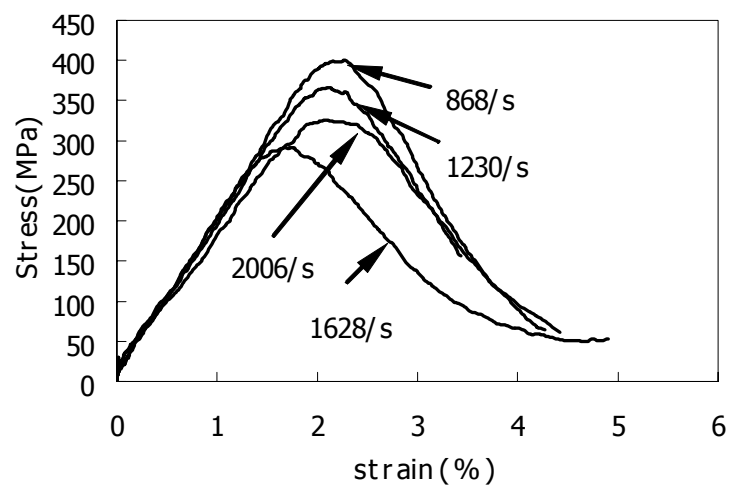

Figure 3: A stress-strain curve of composites with a braid angle of $15^{\circ}$ at high strain rates in the thickness direction.

\subsection{Loading case along the thickness direction}

The stress-strain curve and values of stress and stiffness at high strain rates through the thickness direction for braid angles $15^{\circ}$ and $30^{\circ}$ are presented in Fig. 3 , Fig. 4 and Tables 1 and 2, respectively. It can be seen that the stress is dependent on the strain rate. Fig. 3 and Fig. 4 show the same trend of the peak stress varying with the strain rate. The peak stress decreases with the increase of the strain rate about from $800 / \mathrm{s}$ to $1550 / \mathrm{s}$. and then increases with the strain rate 
at a strain rate of $1800 / \mathrm{s}$. The values of the peak stress of the braid angle at $15^{0}$ are $369.39,395.08,273.02$ and $330.84 \mathrm{MPa}$ for a strain rate of $868,1230,1628$ and 2006/s respectively. And for the strain rates of 845, 1135, 1535 and 1884/s, the corresponding values for the peak stress of the braid angle of $30^{\circ}$ are 379.8 , 273,239 and $366.82 \mathrm{MPa}$. For nearly the same strain rate, the peak stress of the braid angle $15^{\circ}$ is larger than that of $30^{\circ}$, and the effect of the strain rate on stiffness for the braid angle of $30^{\circ}$ is larger than that of $15^{\circ}$. The values of stiffness for a braid angle of $15^{\circ}$ are 18.67, 19.63, 19.66 and 16.85GPa for strain rates of $868,1230,1628$ and 2006/s respectively. For the strain rate of 845,1135 , 1535 and $1884 / \mathrm{s}$, the corresponding values for the stiffness of the braid angle at $30^{\circ}$ are $20.22,14.66,11.96$ and 19.67GPa.

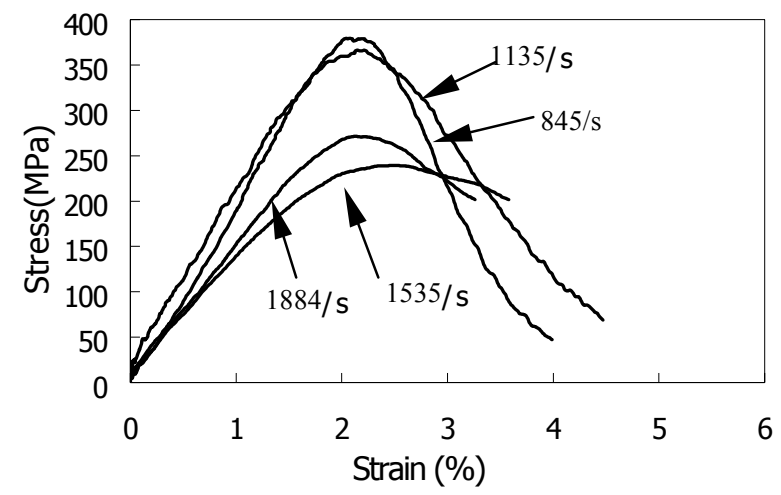

Figure 4: $\quad$ Stress-strain curve of composites with braid angle of $30^{\circ}$ at high strain rates along the thickness direction.

Table 1: The values of peak stress and stiffness along thickness at high strain rates for composite materials with braid angle of $15^{\circ}$.

\begin{tabular}{|c|c|c|}
\hline Strain rate & Peak stress $(\mathrm{MPa})$ & Slope of stress-strain curve $(\mathrm{GPa})$ \\
\hline 868 & 369.39 & 18.67 \\
\hline 1230 & 395.08 & 19.63 \\
\hline 1628 & 273.02 & 19.66 \\
\hline 2006 & 330.84 & 16.85 \\
\hline
\end{tabular}

Table 2: The values of peak stress and stiffness along thickness at high strain rates for composite materials with braid angle of $30^{\circ}$.

\begin{tabular}{|c|c|c|}
\hline Strain rate & Peak stress $(\mathrm{MPa})$ & Slope of stress-strain curve $(\mathrm{GPa})$ \\
\hline 845 & 379.80 & 20.22 \\
\hline 1135 & 273.00 & 14.66 \\
\hline 1535 & 239.60 & 11.96 \\
\hline 1884 & 366.82 & 19.67 \\
\hline
\end{tabular}




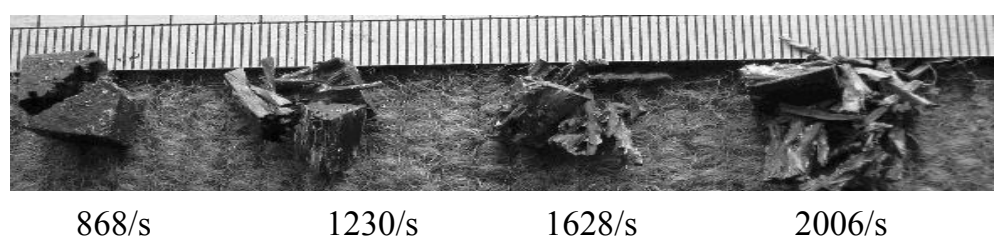

Figure 5: Compressive failure of the braid angle $15^{\circ}$ at various strain rates along thickness direction.

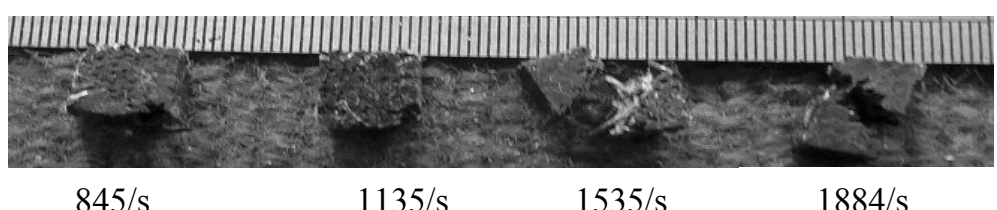

Figure 6: Compressive failure of the braid angle $30^{\circ}$ at various strain rates along the thickness direction.

The compressive failure of the braid angle at $15^{\circ}$ and $30^{\circ}$ along the thickness at high strain rates are shown in Fig. 5 and Fig. 6, respectively. The composites with a braid angle of $15^{\circ}$ damage and fracture more seriously than the braid angle of $30^{\circ}$. The composites with a braid angle of $30^{\circ}$ have a better resistance to breaking into parts than a braid angle of $15^{\circ}$. The compressive failure of a braid angle of $15^{\circ}$ is a shear fracture at a strain rate of $868 / \mathrm{s}$, and is then nearly completely broken at a strain rate of $1230 / \mathrm{s}$. However, the compressive failure of composites with the braid angle of $30^{\circ}$ is an expansion in axial direction from a strain rate of $845 / \mathrm{s}$ to $1135 / \mathrm{s}$, and shear fracture takes place at a strain rate from $1535 / \mathrm{s}$ to $1884 / \mathrm{s}$.

Table 3: The values of peak stress and stiffness along the transverse at high strain rates of composite materials with a braid angle of $15^{\circ}$.

\begin{tabular}{|c|c|c|}
\hline Strain rate & Peak stress $(\mathrm{MPa})$ & Slope of stress-strain curve $(\mathrm{GPa})$ \\
\hline $283 / \mathrm{s}$ & 369.39 & 27.33 \\
\hline $371 / \mathrm{s}$ & 401.51 & 24.87 \\
\hline $465 / \mathrm{s}$ & 414.35 & 23.62 \\
\hline $524 / \mathrm{s}$ & 440.05 & 25.86 \\
\hline
\end{tabular}

Table 4: $\quad$ The values of peak stress and stiffness along the transverse at high strain rates for composite materials with a braid angle of $30^{\circ}$.

\begin{tabular}{|c|c|c|}
\hline Strain rate & Peak stress $(\mathrm{MPa})$ & Slope of stress-strain curve $(\mathrm{GPa})$ \\
\hline $297 / \mathrm{s}$ & 303.56 & 24.32 \\
\hline $356 / \mathrm{s}$ & 324.42 & 23.11 \\
\hline $412 / \mathrm{s}$ & 382.23 & 23.54 \\
\hline $488 / \mathrm{s}$ & 485.02 & 33.36 \\
\hline
\end{tabular}




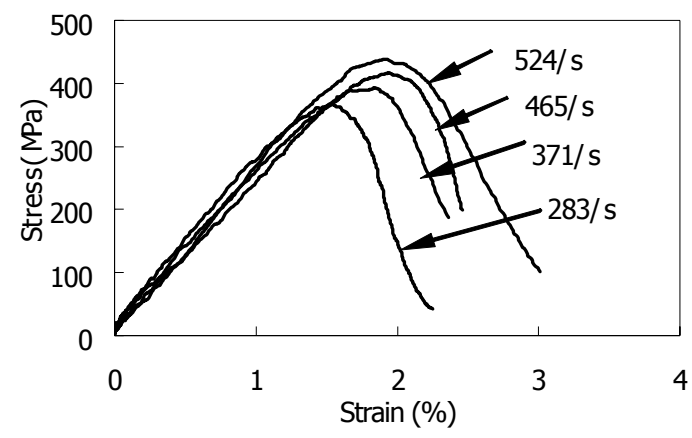

Figure 7: Stress-strain curve of composites with a braid angle of $15^{\circ}$ at a high strain rate along the transverse direction.

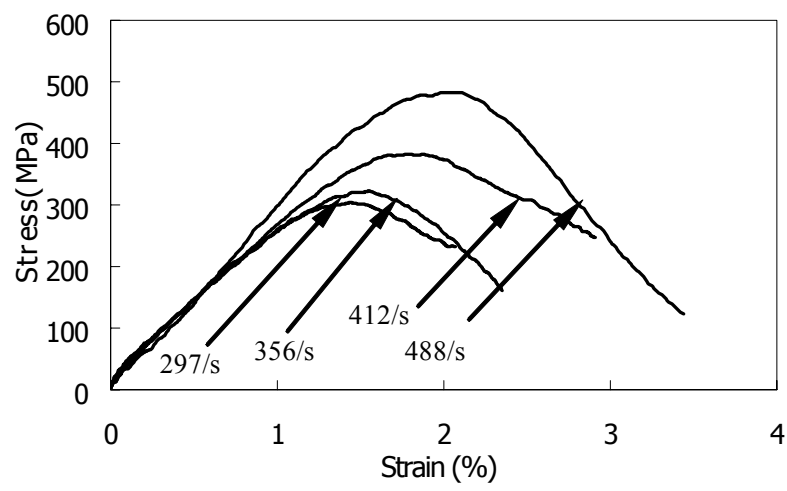

Figure 8: Stress-strain curve of composites with braid angle of $30^{\circ}$ at high strain rate along the transverse direction.

\subsection{Loading along the transverse direction}

The stress-strain curve and the value of stress and stiffness for composites with braid angles of $15^{\circ}$ and $30^{\circ}$ at high strain rates along the transverse direction are presented in Figs. 7 and 8 and Tables 3 and 4 respectively. It can be seen that the stress is dependent on the strain rate. Fig. 7 and Fig. 8 show the same trend of the peak stress varying with the strain rate. The peak stress increases with the increase in strain rate. The values of the peak stress of the braid angle of $15^{\circ}$ are $369.39,401.51,414.35$ and $440.05 \mathrm{MPa}$ for strain rates of 283,371, 465 and $524 / \mathrm{s}$, respectively. For the strain rates of 297, 356, 412 and 488/s, the corresponding value for the peak stress of the braid angle of $30^{\circ}$ are 303.56 , $324.42,382.23$ and $485.02 \mathrm{MPa}$. For almost the same strain rate, the peak stress of a braid angle of $15^{\circ}$ is greater than that of $30^{\circ}$. The effect of the strain rate on the stiffness of braid angles of $30^{\circ}$ and $15^{\circ}$ is small. The stiffness of a braid angle 
of $15^{\circ}$ is slightly larger than that of $30^{\circ}$ at a high strain rate. The values of stiffness for a braid angle of $15^{\circ}$ are $27.33,24.87,23.62$ and $25.86 \mathrm{GPa}$ for strain rates of 283, 371, 465 and 524/s respectively. For a strain rate of 297, 356, 412 and $488 / \mathrm{s}$, the corresponding values for the stiffness of the braid angle at $30^{\circ}$ are 24.32, 23.11, 23.54 and 33.36GPa.

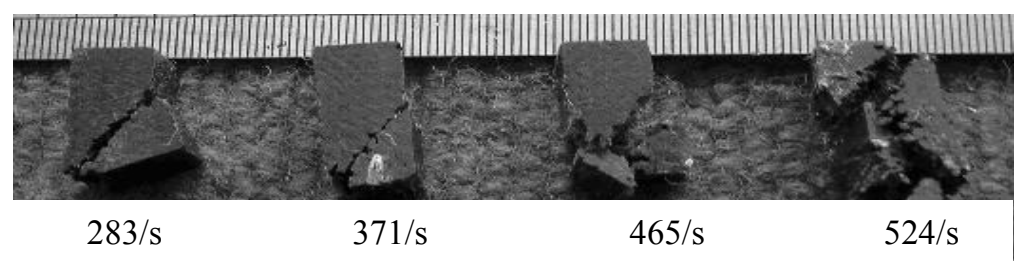

Figure 9: Compressive failure of the braid angle at $15^{\circ}$ at various strain rates along transverse direction.

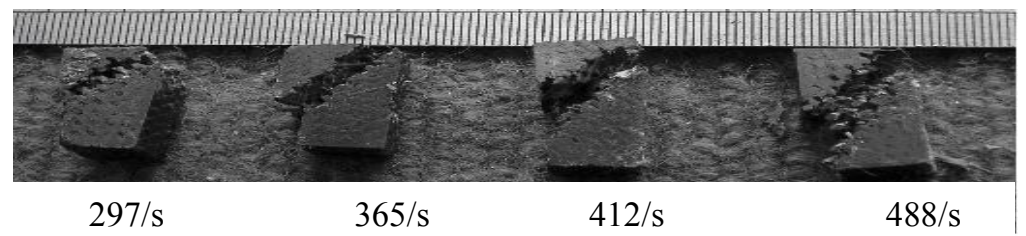

Figure 10: Compressive failure of the braid angle at $30^{\circ}$ at various strain rates along transverse direction.

The compressive failure modes of two braid angles of $15^{\circ}$ and $30^{\circ}$ at high strain rates are shown in Fig. 9 and Fig. 10, respectively. It is clear that both braid angles $15^{\circ}$ and $30^{\circ}$ compressive failure of composites are shear fractures along the braid angle at a high strain rate. The composites with a braid angle of $15^{\circ}$ damage and fracture more seriously than those with a braid angle of $30^{\circ}$. The composites with a braid angle of $30^{\circ}$ have better resistance to breaking into parts than those with a braid angle of $15^{\circ}$.

\section{Summary and conclusion}

Investigations were carried out on carbon/epoxy braid composites with different braid angles along the thickness and transverse directions at high strain rates (up to $2000 / \mathrm{s}$ ) by using a split Hopkinson pressure bar with a pulse shaping technique. The results of two different composites were compared to one another, and the effects of the strain rate and braid angles on the peak stress of the composite were discussed in this paper. The following conclusions were drawn from the study:

(1) For each braid composite material, the peak stress increases along with the increase of the strain rate along the transverse direction. However, the peak stress decreases with the increase in strain rate, and then increases with the increase in strain rate along the thickness direction. 
(2) The effect of the strain rate on the stiffness of the transverse is small, but the effect of the strain rate on the stiffness of thickness is very obvious.

(3) The peak stress and stiffness of the braid angle at $15^{\circ}$ are greater than those with a braid angle of $30^{\circ}$ along both transverse and thickness directions at high strain rates.

\section{References}

[1] Bing, Q.D. \& Sun, C.T., Modeling and testing strain rate-dependent compressive strength of carbon/epoxy composites. Composites Science and Technology, 65, pp.2481-2491, 2005.

[2] Li, Z. \& Lambros, J., Determination of the dynamic response of brittle composites by use of the split Hopkinson pressure bar. Composites Science and Technology, 59, pp.1097-1107, 1996.

[3] Hosur, M.V., Alexander, J., Vaidya, U.K. \& Jeelani, S., High strain rate compression response of carbon/epoxy laminate composites. Composite Structures, 52, pp. 405-417, 2001.

[4] EL-Habak AMA., Compressive resistance of unidirectional GFRP under high strain rate of loading, Journal of Composites Technology. 15(4), pp.311-317, 1993.

[5] Oguni, K. \& Ravichandran, G., Dynamic compressive behavior of unidirectional E-glass/vinylester composites. Journal of Material Science, 36, pp.831-838, 2001.

[6] Wass, A.M., Takeda, N. \& Yuan J., Static and dynamic properties of glass fiber reinforced unidirectional composites. Proceedings $12^{\text {th }}$ Annual Technical American Society for Composites Conference, Dearborn, In: Gibson RF, Newaz GM, editors, pp. 552-561, 1997.

[7] Hosur, M.V., Alexander, J., Vaidya, U.K., Jeelani, S. \& Mayer, A., Studies on the off-axis high strain rate compression loading of satin weave carbon/epoxy composites. Composites Structures, 63, pp. 75-85, 2004.

[8] Ochola, R.O. Marcus, K., Nurick, G.N. \& Franz, T., Mechanic behavior of glass and carbon fiber reinforced composites at varying strain rates. Composites Structures, 63, pp. 455-467, 2004.

[9] Sun, B.Z., Gu, B.H. \& Ding, X., Compressive behavior of 3-D angleinterlock woven fabric composites at various strain rates. Polymer Testing, 24, pp.447-454, 2005.

[10] Mouritz, A.P., Bannister, M.K., Falzon, P.J. \& Leong, K.H., Review of applications for advanced three-dimensional fibre textile composites. Composites Part A, 30, pp. 1445-1461, 1999. 